\title{
Epidemiology of adult-onset hydrocephalus: institutional experience with 2001 patients
}

\author{
Shyamal C. Bir, MD, PhD, Devi Prasad Patra, MD, MCh, Tanmoy K. Maiti, MD, MCh, \\ Hai Sun, MD, PhD, Bharat Guthikonda, MD, Christina Notarianni, MD, and Anil Nanda, MD, MPH \\ Department of Neurosurgery, Louisiana State University Health Sciences Center, Shreveport, Louisiana
}

\begin{abstract}
OBJECTIVE Adult-onset hydrocephalus is not commonly discussed in the literature, especially regarding its demographic distribution. In contrast to pediatric hydrocephalus, which is related to a primary CSF pathway defect, its development in adults is often secondary to other pathologies. In this study, the authors investigated the epidemiology of adult-onset hydrocephalus as it pertains to different etiologies and in reference to age, sex, and race distributions.
\end{abstract}

METHODS The authors retrospectively reviewed the clinical notes of 2001 patients with adult-onset hydrocephalus who presented to Louisiana State University Health Sciences Center within a 25-year span. Significant differences between the groups were analyzed by a chi-square test; $p<0.05$ was considered significant.

RESULTS The overall mean ( \pm SEM) incidence of adult hydrocephalus in this population was $77 \pm 30$ per year, with a significant increase in incidence in the past decade (55 \pm 3 [1990-2003] vs $102 \pm 6$ [2004-2015]; $p<0.0001)$. Hydrocephalus in a majority of the patients had a vascular etiology (45.5\%) or was a result of a tumor $(30.2 \%)$. The incidence of hydrocephalus in different age groups varied according to various pathologies. The incidence was significantly higher in males with normal-pressure hydrocephalus $(p=0.03)$ or head injury $(p=0.01)$ and higher in females with pseudotumor cerebri $(p<0.0001)$. In addition, the overall incidence of hydrocephalus was significantly higher in Caucasian patients $(p=0.0002)$ than in those of any other race.

CONCLUSIONS Knowledge of the demographic variations in adult-onset hydrocephalus is helpful in achieving better risk stratification and better managing the disease in patients. For general applicability, these results should be validated in a large-scale meta-analysis based on a national population database.

http://thejns.org/doi/abs/10.3171/2016.7.FOCUS16188

KEY WORDS adult hydrocephalus; epidemiology; etiopathogenesis

$\mathrm{H}$ YDROCEPHALUS is broadly defined as a disturbance of formation, flow, or absorption of CSF that often is detected when it becomes symptomatic as a result of increased intracranial pressure..$^{23}$ Although common at extremes of ages, it can affect young and middleaged adults with various degrees of severity and presenta- tion. Adult-onset hydrocephalus is not usually an independent entity and is often secondary to different pathologies that encompass a heterogeneous group of disorders such as intracranial hemorrhage, tumor, head injury, and infection..$^{2,24}$ This is in contrast to hydrocephalus in the pediatric age group, in which a majority of cases are caused 
primarily by congenital defects of the CSF pathway. In comparison with pediatric hydrocephalus, which has been a well-discussed topic, the literature on adult-onset hydrocephalus caused by different pathologies is relatively sparse, especially regarding its incidence and demographic variations. In this study, we retrospectively analyzed patients in the Louisiana State University Health Sciences Center-Shreveport (LSUHSC-S) database with adultonset hydrocephalus to investigate the incidence, age, sex, and race distributions of hydrocephalus. The findings of this retrospective study might help to determine individual patient risk based on demographic parameters and individual pathologies that can ultimately guide the management paradigm.

\section{Methods}

This study was performed after approval by the LSUHSC-S institutional review board. The database maintained at LSUHSC-S was searched for all adult patients (aged $\geq 18$ years) who were diagnosed with hydrocephalus between April 1990 and June 2015. Medical charts and imaging studies were reviewed, and data on each patient, including age, sex, ethnicity, and etiology of hydrocephalus, were collected. To avoid a selection bias, all significant differences in patients who developed hydrocephalus were correlated with differences in admission rates for each primary pathology.

The analysis was performed using Statistical Package for Social Sciences version 22.0 software (IBM Corp.). A chi-square test was used to analyze the significant differences in age, sex, and race distributions between the groups; $\mathrm{p}<0.05$ was considered significant.

\section{Results}

\section{Incidence and Demographic Distributions of Adult-Onset Hydrocephalus}

Hydrocephalus was diagnosed in 2001 adult patients between 1990 and 2015; the median age was 58 years (range 18-90 years) (Table 1 and Figs. 1 and 2). The mean ( \pm SEM) overall incidence was $77 \pm 30$ per year. The average incidence per year in the first decade (1990-2003) was $55 \pm 3$, which increased significantly to $102 \pm 6$ in the following decade $(2004-2015)$ ( $\mathrm{p}<0.0001)$. The overall incidence of adult hydrocephalus in the population served by our hospital is estimated to be 17 per year per 100,000 population. Nine hundred eighty-two patients (49\%) were male, and 1019 (51\%) were female. Among the 2001 patients, 1250 (62.5\%) were Caucasian, 722 (36.1\%) were African American, and the rest of the patients were either Hispanic or Asian.

\section{Impact of Demographic Parameters on Hydrocephalus Age}

Overall, although the number of cases was markedly higher in the 6th and 7th decades of life, there was no significant difference in the incidence of hydrocephalus in patients between the decades $(\mathrm{p}=0.43)$ (Tables 2 and 3 and Fig. 3). Similar results were obtained within subgroups of etiologies (vascular $[\mathrm{p}=0.17]$, tumor $[\mathrm{p}=0.18]$,
TABLE 1. Patient demographics

\begin{tabular}{lc}
\hline \multicolumn{1}{c}{ Variable } & Value \\
\hline Total no. of patients & 2001 \\
\hline Overall incidence (mean \pm SEM/yr) & $77 \pm 30$ \\
\hline Incidence & $55 \pm 3$ \\
\hline $1990-2003$ & $102 \pm 6$ \\
\hline $2004-2015$ & 58 \\
\hline Age (yrs) & $18-90$ \\
\hline Median & \\
\hline Range & $982(49)$ \\
\hline Sex (no. [\%]) & $1019(51)$ \\
\hline Male & $1250(62.5)$ \\
\hline Female & $722(36.1)$ \\
\hline Ethnicity (no. [\%]) & $29(1.4)$ \\
\hline Caucasian & \\
\hline African American & $910(45.5)$ \\
\hline Other & $605(30.2)$ \\
\hline Pathology (no. [\%]) & $111(5.5)$ \\
\hline Vascular & $212(10.6)$ \\
\hline Tumor & $70(3.5)$ \\
\hline Meningitis & $93(4.6)$ \\
\hline NPH & \\
\hline Pseudotumor cerebri & \\
\hline Trauma & \\
\hline
\end{tabular}

and meningitis $[p=0.12])$. However, in patients with normal pressure hydrocephalus (NPH), the percentage of cases was significantly higher in the 9 th decade $(p<0.0001)$ than in others. Likewise, a significant number of patients with pseudotumor cerebri were in their fourth decade ( $\mathrm{p}$ $<0.0001$ ). In patients with head injury, the incidence of hydrocephalus was significantly higher in the 3rd decade $(\mathrm{p}=0.01)$ than in the others, although there was no significant difference in admission rates in this age group $(\mathrm{p}$ $=0.83$ ).

\section{Sex}

Overall, there was no significant difference in the incidence of hydrocephalus in patients between both sexes $(p=0.88)$ (Table 4 and Fig. 4). This result was the same when compared within etiology subgroups, such as those of vascular and tumor pathologies. However, the incidence was significantly higher in male patients with meningitis $(\mathrm{p}=0.03)$ and male patients with NPH $(\mathrm{p}=0.03)$. There was no significant difference in admission rates in patients with this diagnosis ( $p=0.2$ for meningitis and for NPH). In contrast, female patients with pseudotumor cerebri $(p$ $<0.0001)$ and male patients with trauma $(p=0.01)$ had significantly higher incidences of hydrocephalus, although this finding could be a result of the significant difference in admission rates ( $\mathrm{p}<0.0001$ for both).

\section{Race}

There was significant difference in the overall inci- 

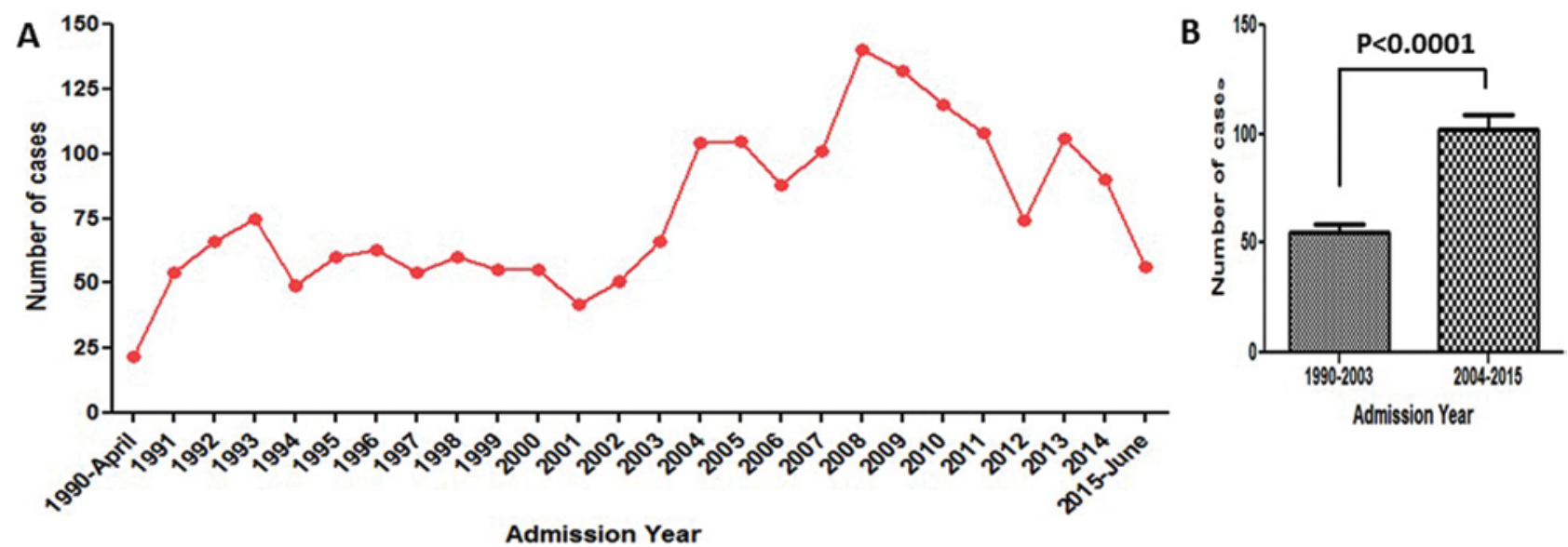

FIG. 1. A: Incidence of adult-onset hydrocephalus according to year of study. B: Increased incidence of hydrocephalus in adults from 1994-2003 to 2004-2015.
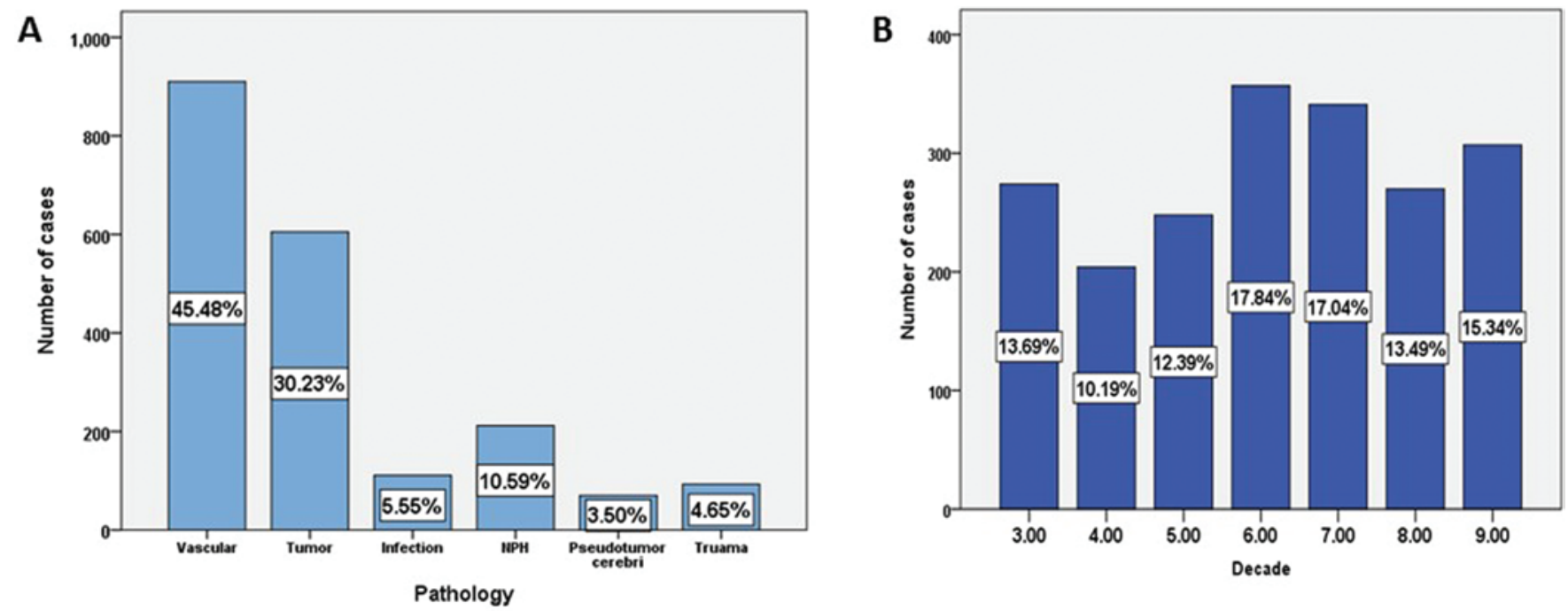

C

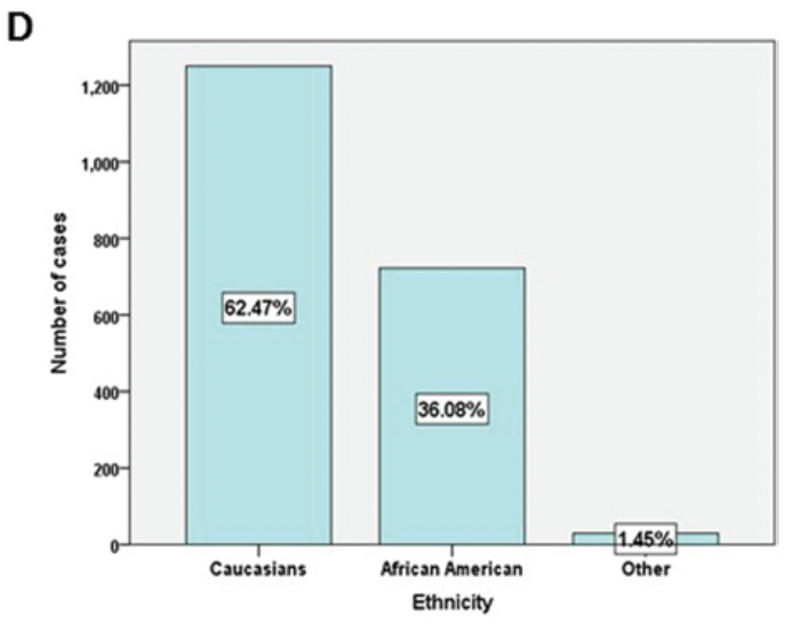

FIG. 2. Overall distribution of adult-onset hydrocephalus according to pathology (A), age (B), sex (C), and race (D), respectively. 
TABLE 2. Age distribution

\begin{tabular}{|c|c|c|c|}
\hline Pathology & $\begin{array}{l}\text { Age at Highest } \\
\text { Incidence } \\
\text { (decade of life) }\end{array}$ & $\mathrm{HR}(95 \% \mathrm{Cl})$ & p Value \\
\hline All & 6th and 7 th & $1.4(0.67-3.18)$ & 0.43 \\
\hline Vascular & 6th and 7 th & $1.8(0.84-3.98)$ & 0.17 \\
\hline Tumor & 6th & $1.8(0.84-3.79)$ & 0.18 \\
\hline Meningitis & $3 r d$ & $1.95(0.90-4.21)$ & 0.12 \\
\hline $\mathrm{NPH}$ & 9th & $11.97(5.26-27.23)$ & $<0.0001^{*}$ \\
\hline $\begin{array}{l}\text { Pseudotumor } \\
\text { cerebri }\end{array}$ & 4th & $6(2.78-12.91)$ & $<0.0001^{*}$ \\
\hline Trauma & $3 r d$ & $2.7(1.28-5.72)$ & $0.01^{*}$ \\
\hline
\end{tabular}

$\mathrm{HR}=$ hazard ratio.

* Significant result. dences of hydrocephalus between the races, with a higher incidence among Caucasian patients $(\mathrm{p}=0.0002)$ (Table 5 and Fig. 5). Similarly, there was a significant difference in race distribution in the patients with hydrocephalus caused by a different pathology, including tumor ( $\mathrm{p}=$ $0.0003)$, meningitis $(\mathrm{p}=0.02), \mathrm{NPH}(\mathrm{p}<0.0001)$, pseudotumor cerebri $(p=0.007)$, and head injury $(p<0.0001)$. However, these results might be attributable to the difference in admission rates, except in patients with meningitis and trauma, for whom admission rates were not significantly different. Caucasian patients had a higher admission rate for hydrocephalus with a vascular pathology $(\mathrm{p}<$ 0.0001); however, the development of hydrocephalus was not significantly different than that in patients with any other pathology.

\section{Demographic Variations in Different Pathologies}

A majority (75.7\%) of the patients had hydrocephalus attributable to a vascular disorder (45.5\%) (e.g., intracranial hemorrhage) or tumor (30.2\%). Other causes included

TABLE 3. Demographics of all admitted patients

\begin{tabular}{|c|c|c|c|}
\hline Pathology \& Demographics & Admitted-Patient Data* & $\mathrm{HR}(95 \% \mathrm{Cl})$ & $\mathrm{p}$ Value \\
\hline \multicolumn{4}{|l|}{ All } \\
\hline Age & 6th and 7 th decade & $1.5(0.68-3.37)$ & 0.35 \\
\hline $\operatorname{Sex}(M / F)$ & $3865 / 4199(48 / 52)$ & $1.49(0.82-2.70)$ & 0.67 \\
\hline Race (Caucasian/African American) & $5266 / 2701(65 / 33)$ & $3.85(2.06-7.33)$ & $<0.0001 \dagger$ \\
\hline \multicolumn{4}{|l|}{ Vascular } \\
\hline Age & 6th and 7th decade & $3.14(1.36-7.80)$ & $0.005 \dagger$ \\
\hline $\operatorname{Sex}(M / F)$ & $668 / 1256(36 / 64)$ & $3.16(1.77-7.3)$ & $<0.0001 \dagger$ \\
\hline Race (Caucasian/African American) & $1256 / 608(67 / 32)$ & $4.34(2.32-8.31)$ & $<0.0001 \dagger$ \\
\hline \multicolumn{4}{|l|}{ Tumor } \\
\hline Age (median) & 6th decade & $1.6(0.73-3.90)$ & 0.25 \\
\hline $\operatorname{Sex}(M / F)$ & $1887 / 2113(47 / 53)$ & $0.78(0.45-5.63)$ & 0.47 \\
\hline Race (Caucasian/African American) & $2679 / 1281(67 / 32)$ & $4.38(2.41-7.59)$ & $<0.0001 \dagger$ \\
\hline \multicolumn{4}{|l|}{ Meningitis } \\
\hline Age & 3rd decade & $0.83(0.33-2.07)$ & 0.83 \\
\hline $\operatorname{Sex}(M / F)$ & $356 / 287(55 / 45)$ & $1.49(0.85-2.60)$ & 0.20 \\
\hline Race (Caucasian/African American) & $328 / 310(51 / 48)$ & $1.12(0.64-1.97)$ & 0.77 \\
\hline \multicolumn{4}{|l|}{ NPH } \\
\hline Age & 9th decade & $5.7(2.55-13.81)$ & $<0.0001 \dagger$ \\
\hline $\operatorname{Sex}(M / F)$ & $117 / 95(55 / 45)$ & $1.49(0.82-2.70)$ & 0.20 \\
\hline Race (Caucasian/African American) & $177 / 32(84 / 15)$ & $29.79(13.23-72.02)$ & $<0.0001 \dagger$ \\
\hline \multicolumn{4}{|l|}{ Pseudotumor cerebri } \\
\hline Age & 4th decade & $4.34(1.95-10.51)$ & $<0.0001 \dagger$ \\
\hline $\operatorname{Sex}(M / F)$ & $14 / 72(16 / 84)$ & $27.56(12.94-58.7)$ & $<0.0001 \dagger$ \\
\hline Race (Caucasian/African American) & $50 / 36(58 / 42)$ & $1.90(1.08-3.34)$ & $0.03+$ \\
\hline \multicolumn{4}{|l|}{ Trauma } \\
\hline Age & 3rd decade & $0.84(0.35-2.03)$ & 0.83 \\
\hline $\operatorname{Sex}(M / F)$ & $823 / 420(66 / 34)$ & $3.7(2.0-6.76)$ & $<0.0001 \dagger$ \\
\hline Race (Caucasian/African American) & $776 / 439(62 / 35)$ & $3.11(1.65-5.88)$ & 0.0001 \\
\hline
\end{tabular}

* Values are decade of life or number/number (\%/\%).

$\dagger$ Significant result. 
meningitis, NPH, pseudotumor cerebri, and head injury in 111 (5.5\%), 212 (10.6\%), 70 (3.5\%), and 93 (4.6\%) patients, respectively (Tables 1 and 6 and Fig. 2).

\section{Vascular Pathology}

The major vascular pathologies were intracranial aneurysm (98.7\%) and arteriovenous malformation (1.3\%) (Fig. 6A). Among patients with a ruptured aneurysm, the hydrocephalus was markedly higher in the 6th or 7th decade of life $(\mathrm{p}=0.17)($ Fig. $6 \mathrm{C}-\mathrm{E})$. There were no significant differences in sex $(p=0.67)$ or race $(p=0.12)$ distributions.

\section{Tumors}

The major neoplastic lesions associated with hydrocephalus, in decreasing order, were hematologic malignancies (28.4\%), gliomas (24.3\%), metastatic brain tumors (17.7\%), meningiomas (9.6\%), schwannomas (5.1\%), and pituitary tumors (5\%) (Fig. 6B). Other tumors were ependymomas $(1.2 \%)$, hemangiomas $(2.1 \%)$, pineal gland tumors $(2.6 \%)$, epidermoid tumors $(1.2 \%)$, thalamic tumors $(0.8 \%)$, and tumors in the brainstem (2\%).

Pituitary Tumors. Among patients with a pituitary tumor, the mean percentage of hydrocephalus was significantly highest in those in their 5th decade of life $(26.7 \%$ vs a mean of $12.2 \%$ for all other decades; $p=0.01$ ) (Fig. $7 \mathrm{~A}-\mathrm{C})$. However, there were no significant differences in sex $(p=0.47)$ and race $(p=0.07)$ distributions.

Meningiomas. The mean percentages of hydrocephalus in the patients with meningioma were highest in patients in their 3rd, 5th, and 7th decades of life $(p=0.10)$ (Fig. 7D-F). There was no significant difference in sex distribution $(p=0.47)$. However, there was a significant difference in the race distribution in these patients $(\mathrm{p}=$ $0.001)$.

Gliomas. Among patients with glioma, the mean percentage of hydrocephalus was highest in patients in their 6th decade of life, although this result was not significant ( $24 \%$ vs a mean of $14 \%$ for all the decades; $\mathrm{p}=0.10$ ) (Fig. $8 \mathrm{~A}-\mathrm{C})$. Similarly, there was no significant difference in sex distribution in these patients $(\mathrm{p}=0.32)$. However, there was a significant difference in race distribution $(69 \%$ in Caucasian patients vs $31 \%$ in all others; $p<0.0001$ ).

Schwannomas. The mean percentage of hydrocephalus in these patients was markedly higher in patients in their 3rd and 6th decades of life (23\% each vs a mean of $13 \%$ for all other decades; $p=0.09$ ) (Fig. 8D-F). Similarly, there were no significant differences in sex $(p=0.20)$ and race $(\mathrm{p}=0.67)$ distributions.
A

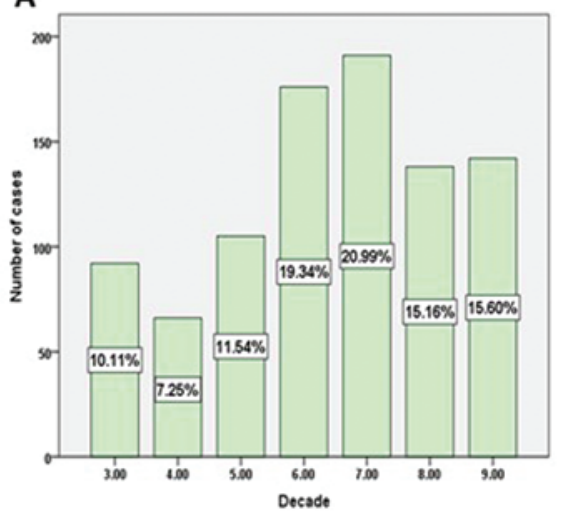

D

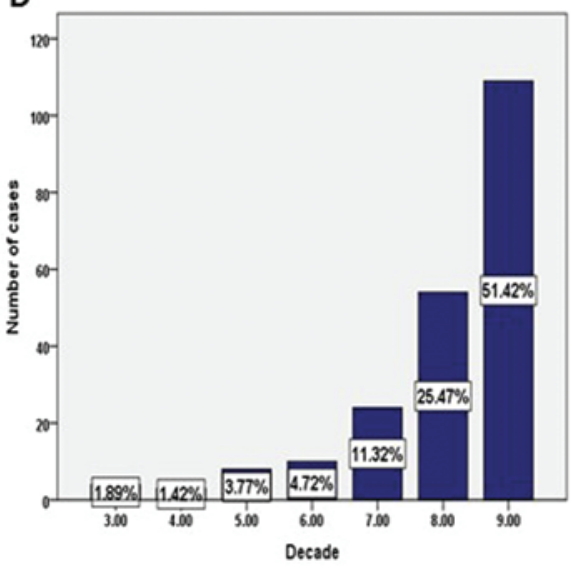

B
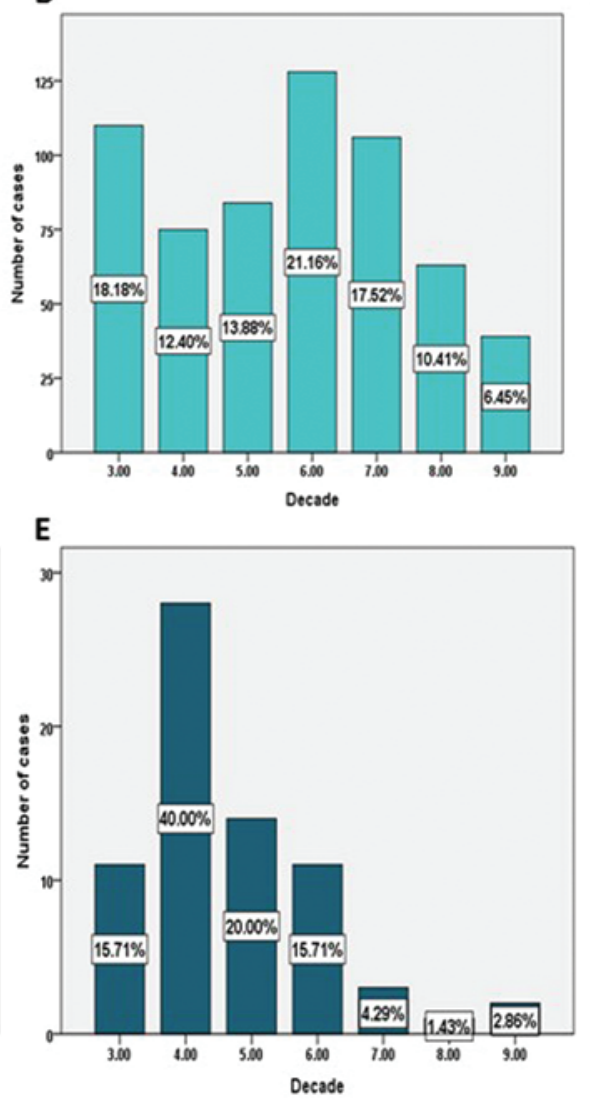

C

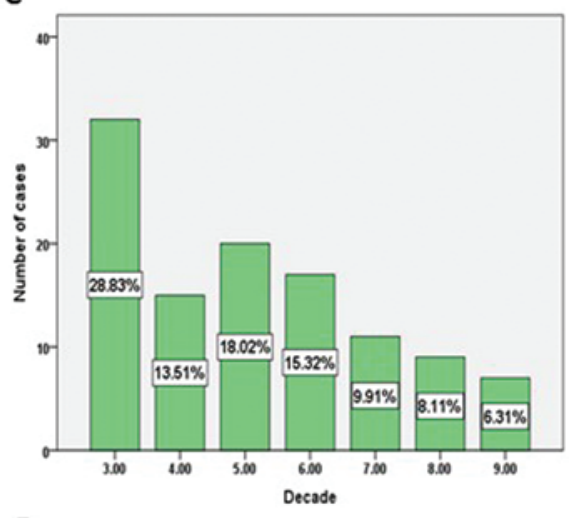

F

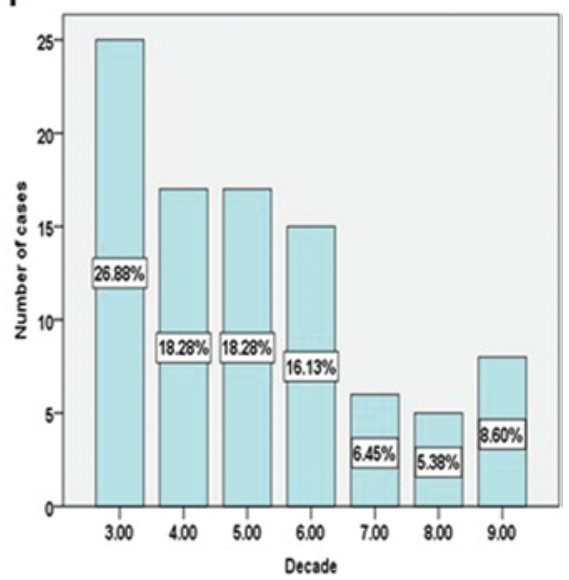

FIG. 3. Distribution of age in different pathologies of adult-onset hydrocephalus: vascular pathologies (A), tumors (B), meningitis (C), NPH (D), pseudotumor cerebri (E), and trauma (F). 
TABLE 4. Sex distribution

\begin{tabular}{lccc}
\hline \multicolumn{1}{c}{ Pathology } & Sex & HR $(95 \% \mathrm{Cl})$ & $\mathrm{p}$ Value \\
\hline All & $\mathrm{M}$ & $0.92(0.53-1.60)$ & 0.88 \\
\hline Vascular & $\mathrm{M}$ & $0.88(0.50-1.54)$ & 0.77 \\
\hline Tumor & $\mathrm{M}$ & $0.72(0.41-1.26)$ & 0.32 \\
\hline Meningitis & $\mathrm{M}$ & $1.90(1.08-3.34)$ & $0.03^{*}$ \\
\hline NPH & $\mathrm{M}$ & $1.91(1.09-3.34)$ & $0.03^{*}$ \\
\hline Pseudotumor cerebri & $\mathrm{F}$ & $44.79(19.64-102)$ & $<0.0001^{*}$ \\
\hline Trauma & $\mathrm{M}$ & $2.57(1.21-5.42)$ & $0.01^{*}$ \\
\hline
\end{tabular}

* Significant result.

Metastatic Brain Tumors. Similar to the pattern of gliomas, there were no statistical differences in age or race distribution, although the mean percentage of hydrocephalus was markedly higher in patients in their 6th decade of life ( $23 \%$ vs a mean of $13 \%$ for all other decades; $p=$ 0.09) (Fig. 9A-C). However, there was a significant difference in the race distribution (65\% in Caucasian patients vs $35 \%$ in Africans American patients; $p<0.0001$ ).

Hematologic Malignancies. The mean percentage of hydrocephalus in patients with a hematologic malignancy was markedly higher in patients in their 6th decade of life than in other decades, but it was not statistically significant (23\% vs a mean of $13 \%$ for all other decades; $p$ $=0.09$ ) (Fig. 9D-F). Similarly, there was no significant difference in the sex distribution in these patients $(\mathrm{p}=$ 0.67). However, there was a significant difference in the race distribution $(61 \%$ in Caucasian patients vs $39 \%$ in others; $\mathrm{p}=0.002$ ).

The admission rates of patients with different tumor types were compared, and we found that there were significant racial differences; there were higher admission rates for Caucasian patients with meningioma, glioma, metastatic brain tumor, or hematologic malignancy $(\mathrm{p}<$ 0.0001 for all). These differences might have contributed to the higher incidence of hydrocephalus in Caucasians.

\section{Discussion}

Hydrocephalus is probably one of the most common pathologic conditions that require neurosurgical intervention. Only very few studies in the existing literature have addressed adult-onset hydrocephalus or its epidemiologic variations.?

\section{Incidence and Prevalence}

The overall incidence of adult-onset hydrocephalus determined in our study was 17 per year per 100,000 population, which is much lower than the incidence of pediatric hydrocephalus, which is 82 per year per 100,000 live births..$^{20}$ In 2005, Tisell et al. ${ }^{25}$ estimated the incidence of adult-onset hydrocephalus requiring surgery to be 3.4 per year per 100,000 population in Sweden. With recent advances and availability of diagnostic tools, an increasing number of cases are being diagnosed early in the disease
A

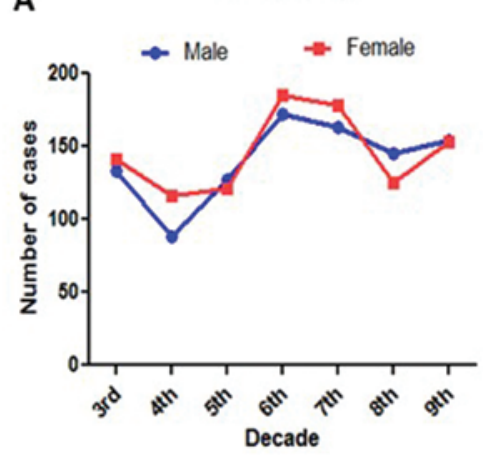

D

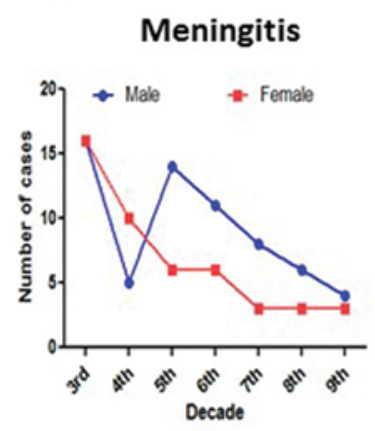

E

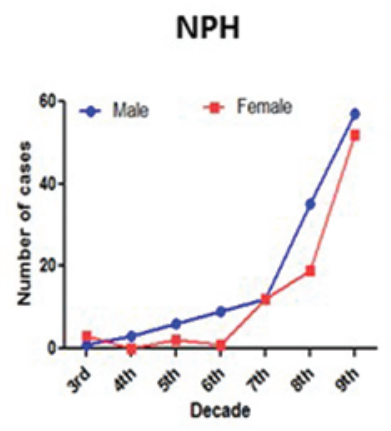

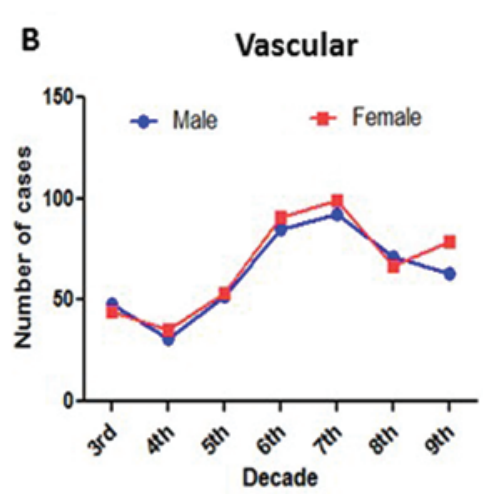

$\mathbf{F}$

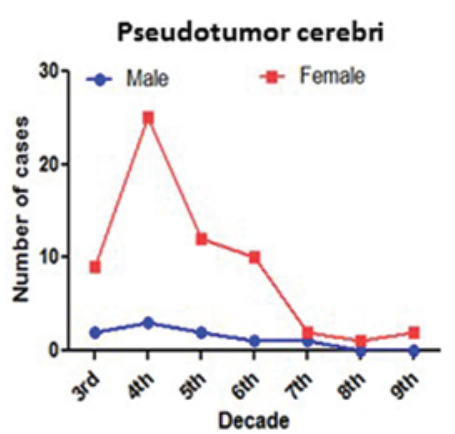

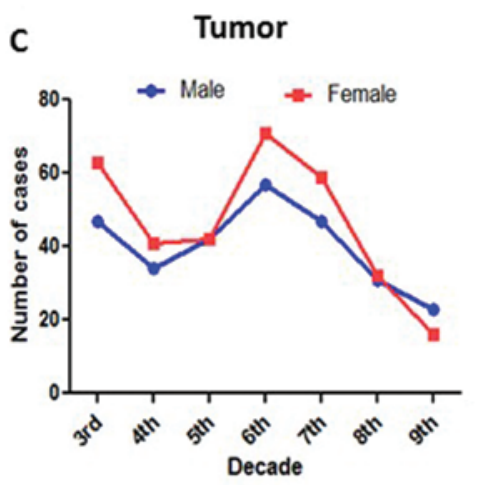

G

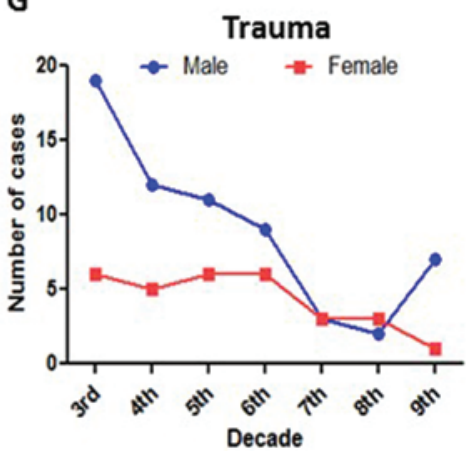

FIG. 4. A-G: Distribution of sex in cases overall and in different pathologies of adult-onset hydrocephalus. 
TABLE 5. Race distribution

\begin{tabular}{lccc}
\hline \multicolumn{1}{c}{ Pathology } & Race & HR $(95 \% \mathrm{Cl})$ & p Value \\
\hline All & Caucasian & $2.92(1.65-5.14)$ & $0.0002^{*}$ \\
\hline Vascular & Caucasian & $1.75(1.0-3.07)$ & 0.06 \\
\hline Tumor & Caucasian & $3.45(1.93-6.17)$ & $0.0003^{*}$ \\
\hline Meningitis & Caucasian & $1.98(1.13-4.48)$ & 0.02 \\
\hline NPH & Caucasian & $27.56(12.94-58.7)$ & $<0.0001^{*}$ \\
\hline Pseudotumor cerebri & Caucasian & $2.25(1.27-52.57)$ & $0.007^{*}$ \\
\hline Trauma & Caucasian & $4.12(2.28-7.34)$ & $<0.0001^{*}$ \\
\hline
\end{tabular}

* Significant result.

course..$^{12,16}$ Similarly, the ease of diagnosis with simple diagnostic procedures such as CT scanning has increased the detection of hydrocephalus from different pathologies. This factor probably has contributed to the sudden increase in incidence from 55 to 102 per year over a decade in our series.

\section{Demographic Variations in Adult-Onset Hydrocephalus of Different Etiologies}

Subarachnoid hemorrhage, NPH, and tumors are the most frequent causes of adult-onset hydrocephalus. ${ }^{7}$ In our series, the most common causes were subarachnoid hemorrhage, tumors, NPH, meningitis, trauma, and pseudotumor cerebri. In addition, the distributions of age, sex, and race in the development of hydrocephalus varied according to the underlying pathology. ${ }^{1}$ The actual incidence of development of hydrocephalus from different pathologies has rarely been reported in the literature. Therefore, we have compared the incidence of hydrocephalus from specific pathologies with the incidence of those pathologies themselves.

\section{Vascular Lesions}

Aneurysms and arteriovenous malformations comprise almost all vascular lesions that produce hydrocephalus secondary to subarachnoid or intraventricular hemorrhage. Hydrocephalus related to vascular events has a more geriatric trend, probably because of the higher incidence of aneurysms, which is relatively common in older age groups, compared with arteriovenous malformations, which affect younger people. In a previous study, the incidence of aneurysm was higher in patients in their 6th decade of life. ${ }^{5}$ It is not surprising that this age group is more vulnerable to developing hydrocephalus, as shown in the present study. It is interesting to note, though, that a previous study ${ }^{5}$ revealed an increased incidence of aneurysms in female patients and in Caucasian patients; however, results from this study population do not reveal any significant association between sex or race in the development of hydrocephalus in these patients.

\section{Tumors}

Excluding pediatric-onset tumors, almost all tumors of the CNS have an increasing trend with increases in age,
A

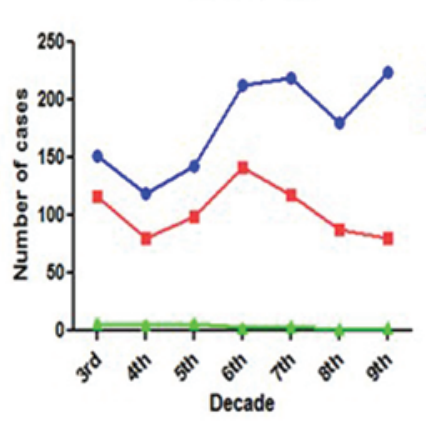

D

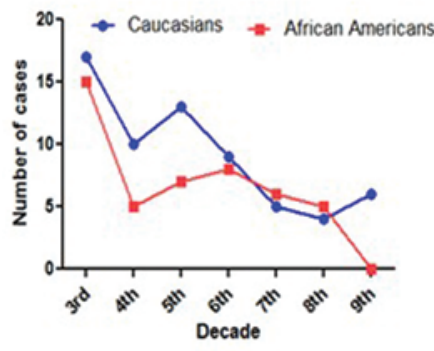

B

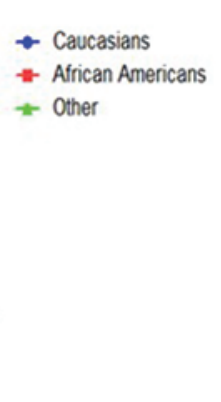

E

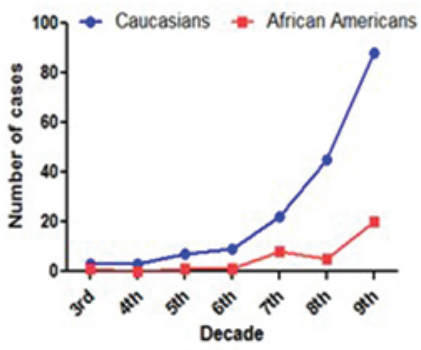

Vascular

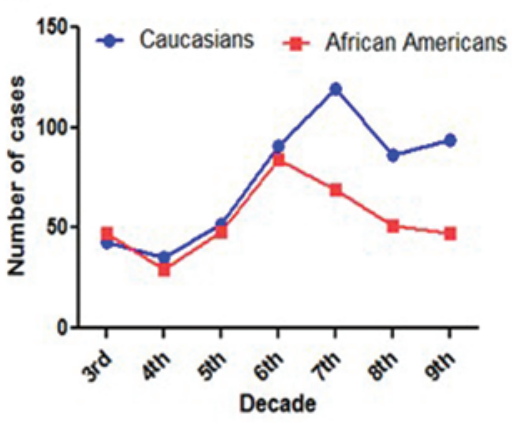

$\mathbf{F}$

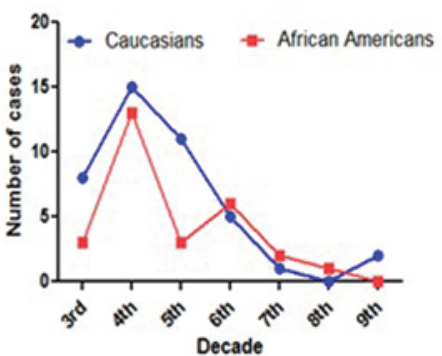

Tumor

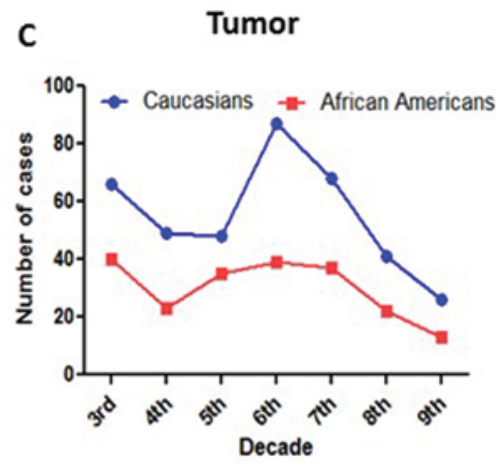

Trauma

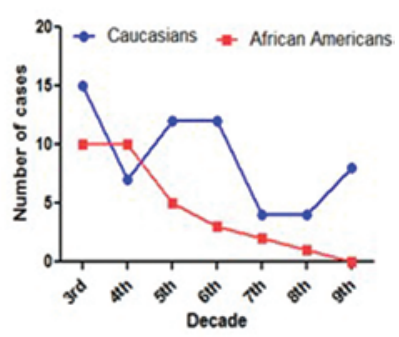

FIG. 5. A-G: Distribution of race in cases overall and in different pathologies of adult-onset hydrocephalus. 
TABLE 6. Differences in age, sex, and race distributions in adultonset hydrocephalus caused by different tumor types*

\begin{tabular}{|c|c|c|c|c|}
\hline Pathology & No. (\%) & Factor & $\mathrm{HR}(95 \% \mathrm{Cl})$ & p Value \\
\hline $\begin{array}{r}\text { Pituitary } \\
\text { tumor }\end{array}$ & $30(5)$ & $\begin{array}{l}\text { Age (5th } \\
\text { decade) }\end{array}$ & $2.7(1.28-5.72)$ & $0.01 \dagger$ \\
\hline Meningioma & $58(9.6)$ & $\begin{array}{l}\text { Caucasian } \\
\text { race }\end{array}$ & $2.6(1.50-4.71)$ & $0.001 \dagger$ \\
\hline Glioma & $147(24.3)$ & $\begin{array}{l}\text { Caucasian } \\
\text { race }\end{array}$ & $4.9(2.72-9.02)$ & $<0.0001 \dagger$ \\
\hline Schwannoma & $31(5.1)$ & - & - & - \\
\hline $\begin{array}{l}\text { Metastatic } \\
\text { brain tumor }\end{array}$ & $107(17.7)$ & $\begin{array}{l}\text { Caucasian } \\
\text { race }\end{array}$ & $3.4(1.9-6.16)$ & $<0.0001 \uparrow$ \\
\hline $\begin{array}{l}\text { Hematologic } \\
\text { malignancy }\end{array}$ & $172(28.4)$ & $\begin{array}{l}\text { Caucasian } \\
\text { race }\end{array}$ & $2.4(1.38-4.31)$ & $0.002 \uparrow$ \\
\hline
\end{tabular}

and the peak incidence is in the 6th-7th decade of life, although the incidence gradually decreases after the age of 85 years. The overall incidence of brain tumors is higher in males than in females (Table 5). ${ }^{10}$ Of gliomas and meningiomas, which are the major subgroup, the gliomas are more common in males and meningiomas are more common in females. ${ }^{19,27}$ The white (Caucasian) race has been shown to be at moderate-to-high risk for gliomas, although a similar association is not evident for meningiomas. Based on tumor occurrence, a similar pattern is expected in the incidence of hydrocephalus in these patients. Hydrocephalus resulting from a glioma had a peak incidence in the 6th decade. ${ }^{8}$ It was more common in Caucasians; however, an association with sex was not found. The incidence of hydrocephalus resulting from a meningioma depends on the location of the tumor, with increased development with infratentorial and intraventricular tumors. ${ }^{17,22}$ Although in this series we did not stratify the incidence based on location, the overall incidence in patients with a meningioma was higher in very young (3rd decade) or older (6th and 7th
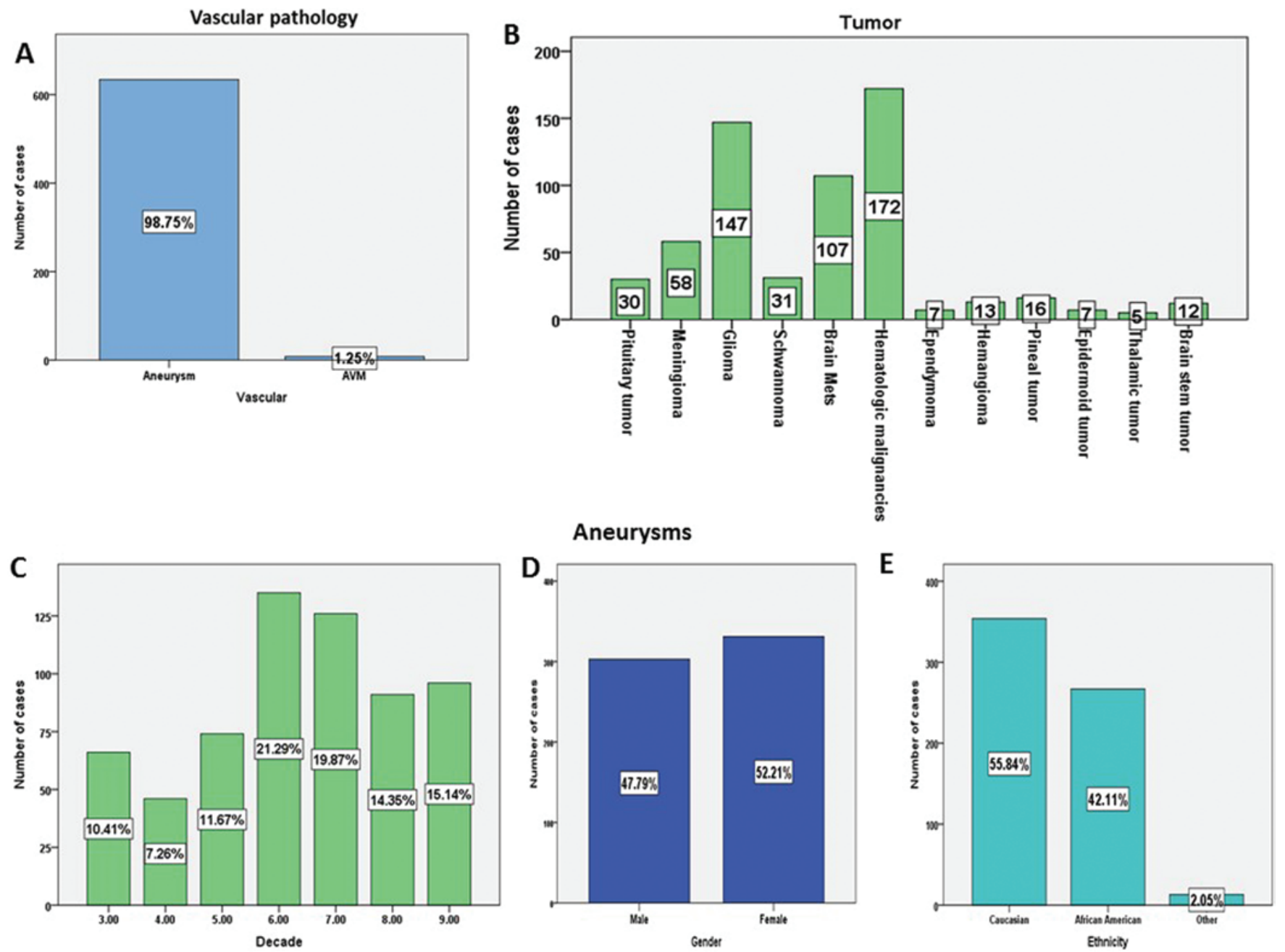

FIG. 6. A: Different vascular causes of adult-onset hydrocephalus. AVM = arteriovenous malformation. B: Different types of tumors that cause adult-onset hydrocephalus. Mets = metastasis. C-E: Age, sex, and race distributions in cases of adult-onset hydrocephalus caused by a ruptured aneurysm. 

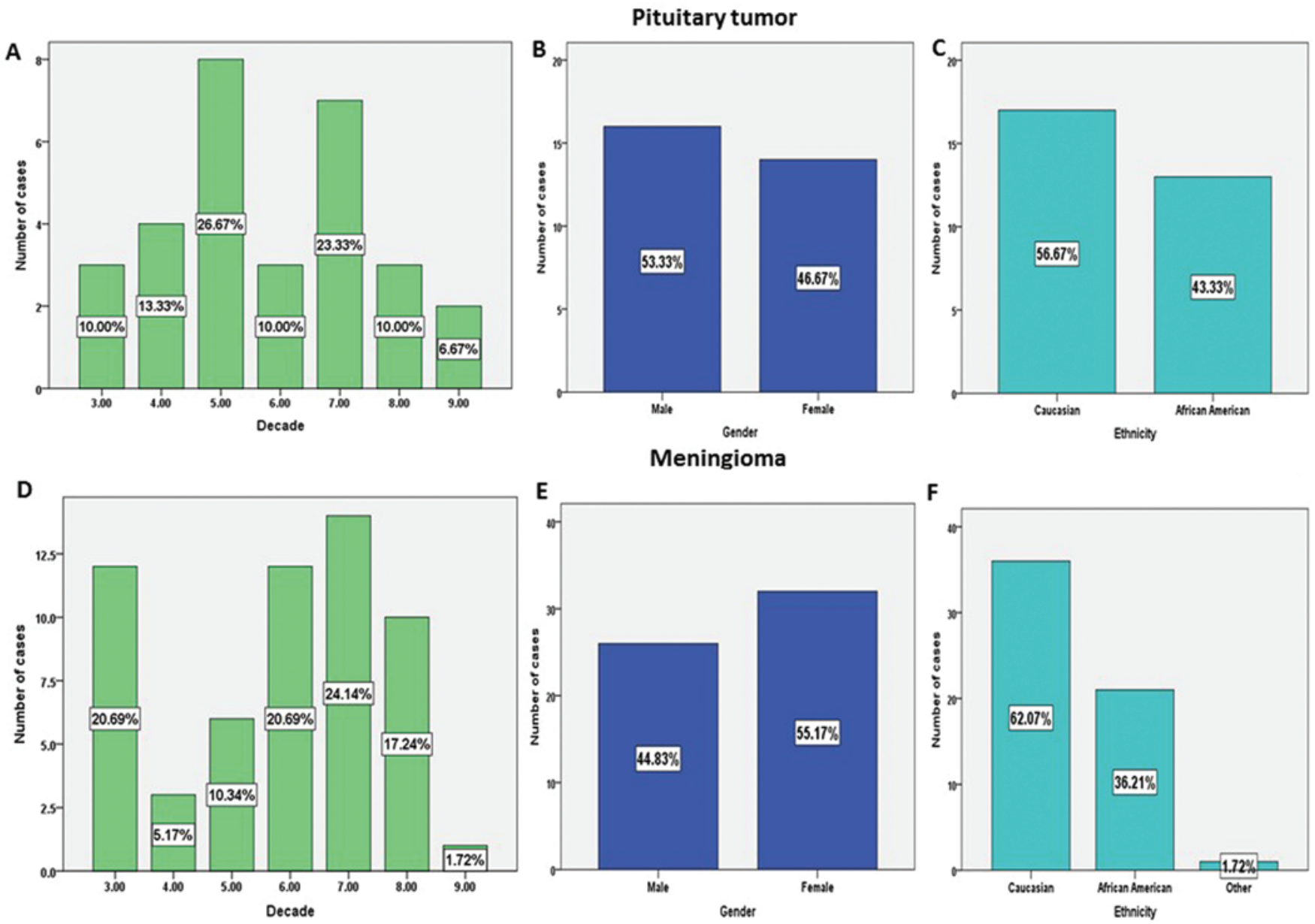

FIG. 7. A-C: Age, sex, and race distributions, respectively, in adult-onset hydrocephalus caused by pituitary tumor. D-F: Age, sex, and race distributions, respectively, in adult-onset hydrocephalus caused by meningioma.

decades) age groups. Similar to the pattern for gliomas, it was more common in Caucasians, although there was no significant difference in the sex distribution.

Among intracranial tumors, the incidence of pituitary tumors is $10 \%-15 \% .{ }^{26}$ Giant pituitary tumors can cause hydrocephalus. ${ }^{14}$ In this series, hydrocephalus caused by a pituitary tumor was $5 \%$, with peak incidence in the 5 th decade of life and no significant variation in sex or race distribution. Schwannomas, especially vestibular schwannomas, can give rise to hydrocephalus, which can be both obstructive and communicating in nature. ${ }^{21}$ In their epidemiologic study of vestibular schwannomas in a US population, Kshettry et al. ${ }^{15}$ found that the peak overall incidence was between 65 and 74 years of age, with a higher incidence in Caucasian than in African American patients. In this study, however, the peak incidence of hydrocephalus in these patients was in the 3rd and 6th decades. There were no differences in the sex and race distributions.

Approximately $20 \%$ of all cases of metastatic brain tumor occur in the posterior fossa, cerebellum, or brainstem and thus leave patients more prone to developing hydrocephalus. ${ }^{11,12}$ The incidence of metastatic brain tumors is higher in the elderly population and in Caucasians, and no sex difference has been found. ${ }^{4} \mathrm{~A}$ similar distribution was observed for the development of hydrocephalus in these patients. Hematologic malignancies such as lymphoma can cause generalized hydrocephalus. ${ }^{9}$ In addition, hydrocephalus can develop during chemotherapy. Chronic lymphocytic lymphomas are more common in elderly patients, and leukemias are more common in younger patients. In this series, the hydrocephalus in these patients peaked in the 3rd and 6th decades of life. Although there is variability in the sex distribution in different types of hematologic malignancies, these cancers are more common in Caucasians. Likewise, in this study, the incidence of hydrocephalus was significantly higher in Caucasian patients with a hematologic malignancy.

Infection

Meningitis and ventriculitis are among the common causes of hydrocephalus because of decreased CSF absorption in the meninges. It is more common in developing countries, especially in tuberculosis-endemic areas. The incidence of hydrocephalus secondary to meningitis was found to be more common in younger age groups (3rd 

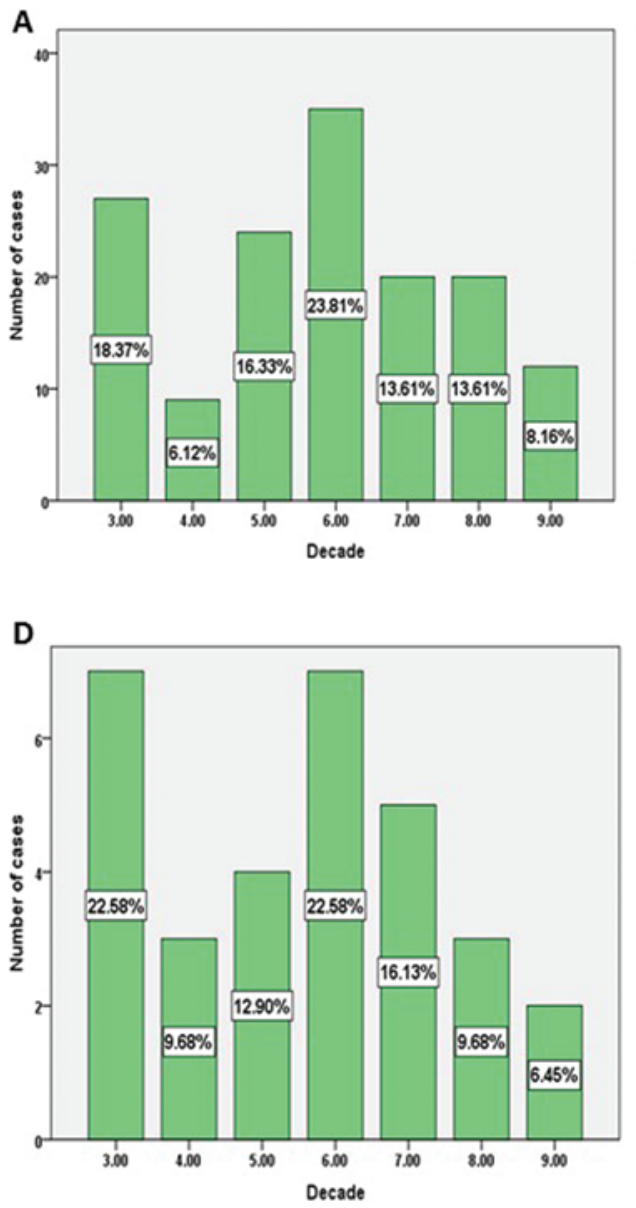
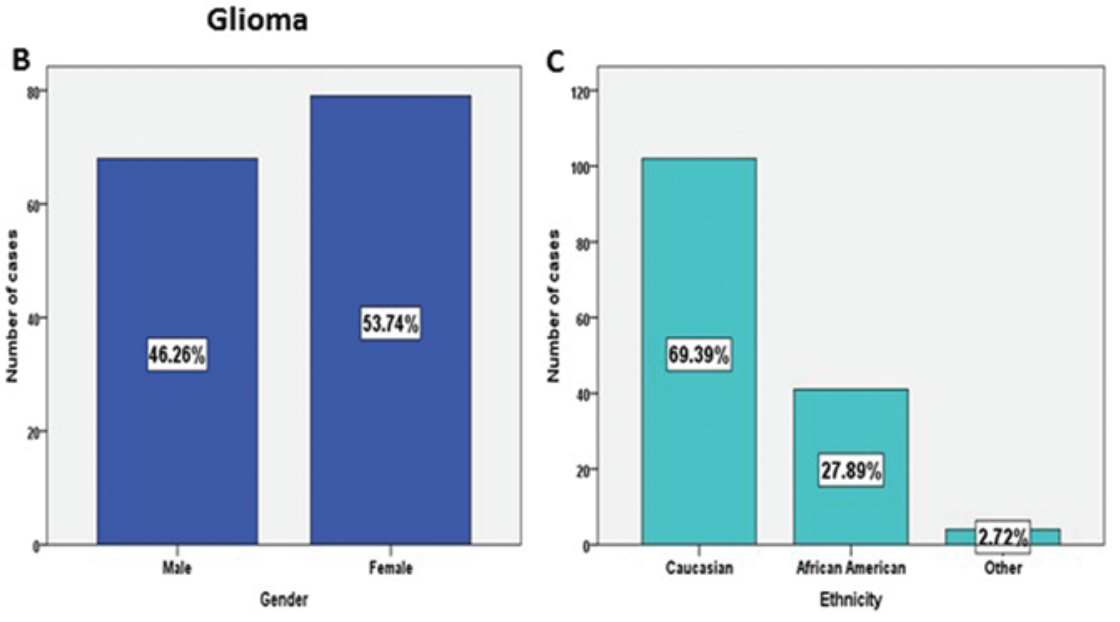

Schwannoma

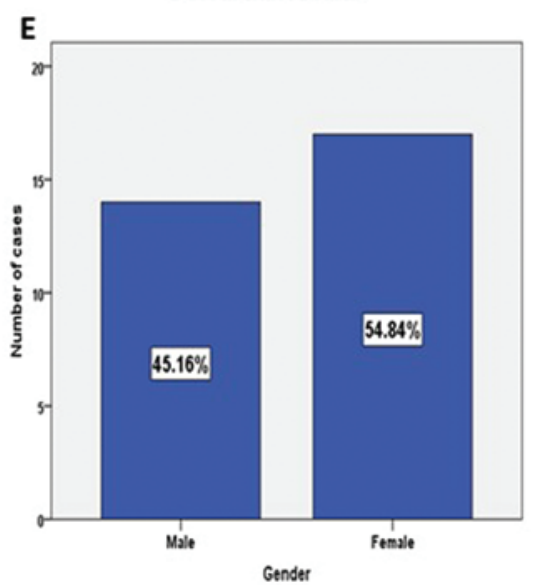

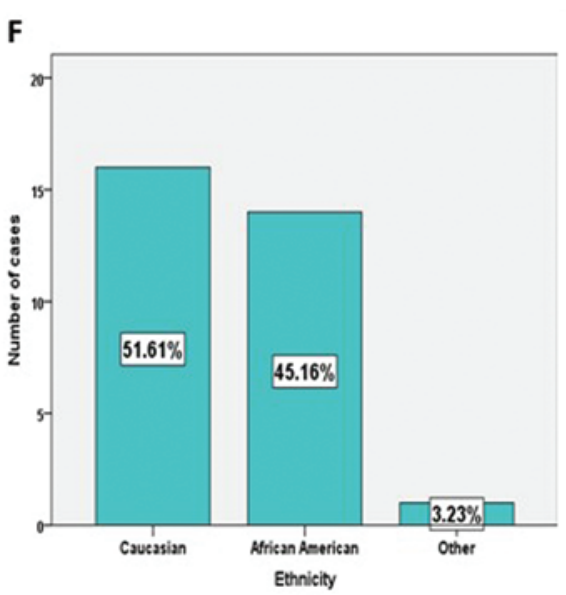

FIG. 8. A-C: Age, sex, and race distributions, respectively, in adult-onset hydrocephalus caused by glioma. D-F: Age, sex, and race distributions, respectively, in adult-onset hydrocephalus caused by schwannoma.

decade) and occurred at a significantly higher rate in Caucasians.

\section{Normal Pressure Hydrocephalus}

Normal pressure hydrocephalus is another important cause of adult hydrocephalus and is considered a disease of the elderly with a less clear pathophysiology. ${ }^{6,13}$ The peak incidence of NPH in our series, in the 9th decade of life, was significantly different than that in other age groups. It predominantly affected males and Caucasians.

\section{Pseudotumor Cerebri}

Pseudotumor cerebri is an entity characterized by increased intracranial pressure with slightly dilated or nondilated ventricles. In a majority of cases, it is idiopathic and affects females of child-bearing age. ${ }^{3}$ Similar to this general trend, in our series, it was predominant in the 4th decade of life and in females. Again, it affected Caucasians significantly.

\section{Trauma}

The highest incidence of hydrocephalus in head injury was in the 3rd decade of life. ${ }^{28}$ Younger people usually travel more and are prone to motor vehicle accidents, which might explain the younger age distribution in patients with head injury. For a similar reason, males have a higher incidence than females. ${ }^{18,28}$ Among the races, Caucasians had a higher incidence of trauma-related hydrocephalus.

\section{Limitations}

Our study has inherent limitations because of its retrospective nature. In addition, the practice patterns of the senior author (A.N.), which include a preponderance of skull base tumor and vascular surgeries, might have contributed to the higher number of vascular and tumor pathologies of adult-onset hydrocephalus in this population. In some instances, variability in the incidence of hydrocephalus among different age, race, and sex groups might be attributable to a difference in admission rates for patients with a primary pathology. The results may have limited application in the general population and therefore must be validated in a large-scale meta-analysis using a national database. 

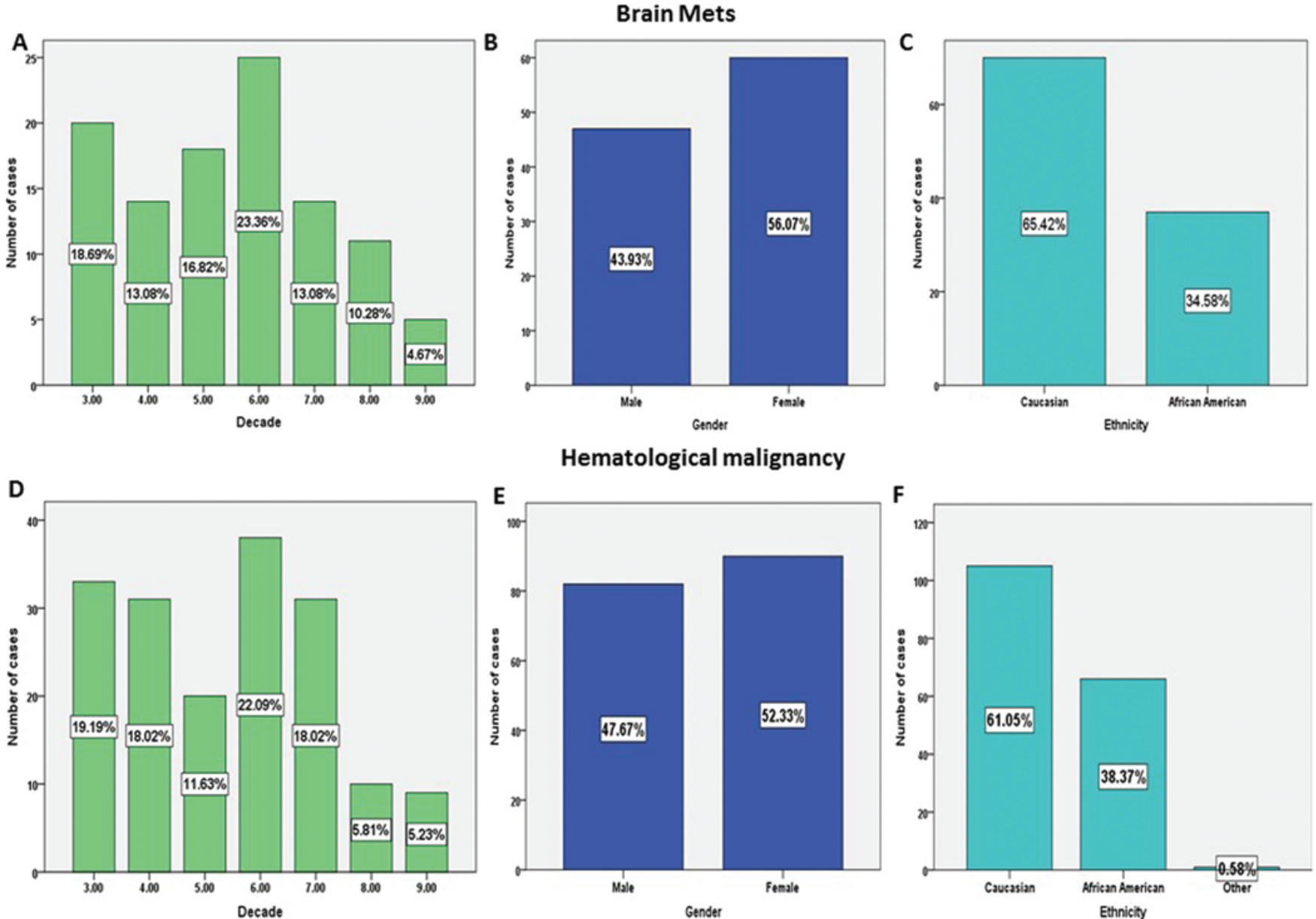

FIG. 9. A-C: Age, sex, and race distributions, respectively, in adult-onset hydrocephalus caused by metastatic brain tumor. D-F: Age, sex, and race distributions, respectively, in adult-onset hydrocephalus caused by hematologic malignancy.

\section{Conclusions}

The demographic variations in patients with adult-onset hydrocephalus is a less-studied topic in the present literature. Knowledge on age, sex, and racial disparities in individual etiologies might help in risk stratification. In addition, it might enlighten the future identification of genetic and environmental factors among different sexes and ethnicities that would provide some insights for better understanding and control of the disease.

\section{References}

1. Attenello FJ, Ng A, Wen T, Cen SY, Sanossian N, Amar AP, et al: Racial and socioeconomic disparities in outcomes following pediatric cerebrospinal fluid shunt procedures. J Neurosurg Pediatr 15:560-566, 2015

2. Bergsneider M, Miller C, Vespa PM, Hu X: Surgical management of adult hydrocephalus. Neurosurgery 62 (Suppl 2):643-660, 2008

3. Biousse V: Idiopathic intracranial hypertension: diagnosis, monitoring and treatment. Rev Neurol (Paris) 168:673-683, 2012

4. Bir SC, Ambekar S, Nanda A: Long term outcome of Gam- ma Knife radiosurgery for metastatic brain tumors. J Clin Neurosci 21:2122-2128, 2014

5. Bir SC, Bollam P, Nanda A: Distribution of ABO blood groups in the patients with intracranial aneurysm and association of different risk factors with particular blood type. Asian J Neurosurg 10:153-157, 2015

6. Brean A, Eide PK: Prevalence of probable idiopathic normal pressure hydrocephalus in a Norwegian population. Acta Neurol Scand 118:48-53, 2008

7. Chahlavi A, El-Babaa SK, Luciano MG: Adult-onset hydrocephalus. Neurosurg Clin N Am 12:753-760, ix, 2001

8. Dubrow R, Darefsky AS: Demographic variation in incidence of adult glioma by subtype, United States, 1992-2007. BMC Cancer 11:325, 2011

9. Elder JB, Chen TC: Surgical interventions for primary central nervous system lymphoma. Neurosurg Focus 21(5):E13, 2006

10. Fisher JL, Schwartzbaum JA, Wrensch M, Wiemels JL: Epidemiology of brain tumors. Neurol Clin 25:867-890, 2007

11. Ghods AJ, Munoz L, Byrne R: Surgical treatment of cerebellar metastases. Surg Neurol Int 2:159, 2011

12. Inskip PD, Hoover RN, Devesa SS: Brain cancer incidence trends in relation to cellular telephone use in the United States. Neuro Oncol 12:1147-1151, 2010

13. Jaraj D, Rabiei K, Marlow T, Jensen C, Skoog I, Wikkelsø 
C: Prevalence of idiopathic normal-pressure hydrocephalus. Neurology 82:1449-1454, 2014

14. Joshi SM, Chopra IS, Powell M: Hydrocephalus caused by giant pituitary tumors: case series and guidelines for management. Br J Neurosurg 23:30-32, 2009

15. Kshettry VR, Hsieh JK, Ostrom QT, Kruchko C, BarnholtzSloan JS: Incidence of vestibular schwannomas in the United States. J Neurooncol 124:223-228, 2015

16. Massimi L, Paternoster G, Fasano T, Di Rocco C: On the changing epidemiology of hydrocephalus. Childs Nerv Syst 25:795-800, 2009

17. Modha A, Gutin PH: Diagnosis and treatment of atypical and anaplastic meningiomas: a review. Neurosurgery 57:538550,2005

18. Mosavi-Jarrahi A, Esteghamati A, Asgari F, Heidarnia M, Mousavi-Jarrahi Y, Goya M: Temporal analysis of the incidence of meningitis in the Tehran metropolitan area, 19992005. Popul Health Metr 7:19, 2009

19. Nanda A, Bir SC, Maiti TK, Konar SK, Missios S, Guthikonda B: Relevance of Simpson grading system and recurrencefree survival after surgery for World Health Organization Grade I meningioma. J Neurosurg [epub ahead of print April 8, 2016. DOI: 10.3171/2016.1.JNS151842]

20. Persson EK, Anderson S, Wiklund LM, Uvebrant P: Hydrocephalus in children born in 1999-2002: epidemiology, outcome and ophthalmological findings. Childs Nerv Syst 23:1111-1118, 2007

21. Pirouzmand F, Tator CH, Rutka J: Management of hydrocephalus associated with vestibular schwannoma and other cerebellopontine angle tumors. Neurosurgery 48:12461254,2001

22. Raimondi AJ, Tomita T: Hydrocephalus and infratentorial tumors. Incidence, clinical picture, and treatment. J Neurosurg 55:174-182, 1981

23. Rekate HL: A contemporary definition and classification of hydrocephalus. Semin Pediatr Neurol 16:9-15, 2009

24. Riva-Cambrin J, Detsky AS, Lamberti-Pasculli M, Sargent
MA, Armstrong D, Moineddin R, et al: Predicting postresection hydrocephalus in pediatric patients with posterior fossa tumors. J Neurosurg Pediatr 3:378-385, 2009

25. Tisell M, Höglund M, Wikkels $\varnothing$ C: National and regional incidence of surgery for adult hydrocephalus in Sweden. Acta Neurol Scand 112:72-75, 2005

26. Villwock JA, Villwock M, Deshaies E, Goyal P: Significant increases of pituitary tumors and resections from 1993 to 2011. Int Forum Allergy Rhinol 4:767-770, 2014

27. Wiemels J, Wrensch M, Claus EB: Epidemiology and etiology of meningioma. J Neurooncol 99:307-314, 2010

28. Zangooei Dovom H, Shafahi Y, Zangooei Dovom M: Fatal accident distribution by age, gender and head injury, and death probability at accident scene in Mashhad, Iran, 20062009. Int J Inj Contr Saf Promot 20:121-133, 2013

\section{Disclosures}

The authors report no conflict of interest concerning the materials or methods used in this study or the findings specified in this paper.

\section{Author Contributions}

Conception and design: Bir, Patra, Maiti. Acquisition of data: Bir. Analysis and interpretation of data: Bir, Patra, Maiti. Drafting the article: Bir, Patra, Maiti. Critically revising the article: all authors. Reviewed submitted version of manuscript: all authors. Approved the final version of the manuscript on behalf of all authors: Nanda. Statistical analysis: Bir. Administrative/technical/material support: Nanda. Study supervision: Nanda.

\section{Correspondence}

Anil Nanda, Department of Neurosurgery, Louisiana State University Health Sciences Center, 1501 Kings Highway, Shreveport, LA 71103-33932. email: ananda@1suhsc.edu. 